\title{
Diagnosing the dangerous demography of manta rays using life history theory
}

Background The directed harvest and global trade in the gill plates of mantas, and devil rays, has led to increased fishing pressure and steep population declines in some locations. The slow life history, particularly of the manta rays, is cited as a key reason why such species have little capacity to withstand directed fisheries. Here, we place their life history and demography within the context of other sharks and rays. Methods Despite the limited availability of data, we use life history theory and comparative analysis to estimate the intrinsic risk of extinction (as indexed by the maximum intrinsic rate of population increase $r_{\text {max }}$ ) for a typical generic manta ray using a variant of the classic Euler-Lotka demographic model. This model requires only three traits to calculate the maximum intrinsic population growth rate $r_{\text {max }}$ : von Bertalanffy growth rate, annual pup production and age at maturity. To account for the uncertainty in life history parameters, we created plausible parameter ranges and propagate these uncertainties through the model to calculate a distribution of the plausible range of $r_{\text {max }}$ values. Results The maximum population growth rate $r_{\text {max }}$ of manta ray is most sensitive to the length of the reproductive cycle, and the median $r_{\max }$ of 0.116 year $^{-1}(\mathrm{Cl}: 0.089-0.139)$ is one of the lowest known of the 106 sharks and rays for which we have comparable demographic information. Discussion In common with other unprotected, unmanaged, high-value large-bodied sharks and rays this combination of very low population growth rates of manta rays, combined with the high value of their gill rakers and the international nature of trade, is highly likely to lead to rapid depletion and local extinction unless a rapid conservation management response occurs worldwide. Furthermore, we show that it is possible to derive important insights into the demography extinction risk of data-poor species using well-established life history theory. 


\section{Diagnosing the dangerous demography of manta rays using life history theory}

2 Nicholas K. Dulvy ${ }^{*}$, Sebastián A. Pardo ${ }^{1}$, Colin A. Simpfendorfer ${ }^{2}$, and John K. Carlson ${ }^{3}$

$3 \quad{ }^{1}$ Earth to Ocean Research Group, Department of Biological Sciences, Simon Fraser University,

4 Burnaby, British Columbia V5A 1S6, Canada,

$5 \quad{ }^{2}$ Centre for Sustainable Tropical Fisheries and Aquaculture \& School of Earth and

6 Environmental Sciences, James Cook University, Townsville, Australia.

$7 \quad{ }^{3}$ NOAA/National Marine Fisheries Service, Southeast Fisheries Science Center, 3500 Delwood

8 Beach Road, Panama City, FL 32408, USA

9 *Corresponding author | Nicholas K. Dulvy, Earth to Ocean Research Group, Department of

10 Biological Sciences, Simon Fraser University, Burnaby, British Columbia V5A 1S6, Canada, Tel:

$11+1-778782-4124$, Email: dulvy@sfu.ca

12 Keywords | Chinese Medicine, CITES, data-poor fisheries, wildlife trade, life history invariant, 13 Mobula.

\section{Introduction}


15 The rapid rise in demand for plant and animal products that are traded through international networks has globalised the reach of economically-powerful consumers causing unsustainable depletion of biological resources (Berkes et al. 2006; Lenzen et al. 2012). While we have long understood the challenges of poaching for the illegal ivory trade (Phillis et al. 2013), we are only now just beginning to reveal the enormous scale of trade in aquatic organisms, such as for the live food fish trade (Sadovy \& Vincent 2002), and the dried product trade in shark fins (Clarke et al. 2006), seahorses (Foster \& Vincent 2004), sea cucumbers (Anderson et al. 2011), and fish swim bladders (larke 2004; Sadovy \& Cheung 2003).

A recent emerging international trade in manta and devil ray gill plates is driving overexploitation elevating their extinction risk (IUCN/TRAFFIC 2013). The high value of gill plates and the international nature of the trade are driving roving bandit dynamics, incentivising serial depletion and a globalized tragedy of the commons (Berkes et al. 2006). If the population growth rate of manta rays is low this pattern of exploitation could lead to rapid depletions and local extinction of manta populations. There are two described species of manta ray Manta birostris (Walbaum, 1792), and M. alfredi (Krefft, 1868) and at least some of the nine devil rays (Mobula spp.) are reported in national catch statistics and appear in international trade (CITES 2007; $\underline{\text { Couturier et }}$ al. 2012; Ward-Paige et al. 2013). Manta and devil rays are taken in targeted fisheries and also as a valuable retained bycatch in China, Ghana, India, Indonesia, Mexico, Peru, Philippines, Sri Lanka and Thailand (Couturier et al. 2012; IUCN/TRAFFIC 2013). Over the past decade the landings of manta and devil rays have risen more than 10-fold from less than 200 tonnes (t) per year in 1998 to a peak of over 5,000 t in 2009 (Ward-Paige et al. 2013). Manta and devil rays are captured for their gill plates and a single mature animal can yield up to $7 \mathrm{~kg}$ of gillrakers which can be worth as much as $\$ 680$ per $\mathrm{kg}$ in Chinese medicine (Heinrichs et al. 2011; IUCN/TRAFFIC 2013). Much of the international trade goes to southern China, and to Chinese communities in other countries (Couturier et al. 2012; Heinrichs et al. 2011). For example, one of the authors has seen devil ray gill plates for sale for $\$ 396.80$ per $\mathrm{kg}$ (under the incorrect taxonomic name Dasyatis Centroura) in Vancouver, Canada 2013 (Figure 1). The trade is currently difficult to monitor because of a lack of international trade codes and species-specific 43 catch and landings data. Despite this, $\sim 21,000 \mathrm{~kg}$ of dried Manta spp. gill plates are traded 44 annually, derived from an estimated $>4,500$ individual manta rays, and worth US \$5 million 45 (Heinrichs et al. 2011; O’Malley et al. 2013). 
46 Many (46\%) of chondrichthyans are Data Deficient (Dulvy et al. 2014), and in comparison to the

47 data-sufficient species we know little of the life history of manta rays Manta birostris (Walbaum

48 1792), and M. alfredi (Krefft, 1868). This is particularly problematic when their viability is

49 threatened by rapidly emerging fisheries driven by international trade demand, and CITES Non-

50 Detriment Findings are required for continued international trade (Clarke 2004; Couturier et al.

51 2012). Both manta rays were listed as Vulnerable on the International Union for the Conservation

52 of Nature Red List of Threatened Species in 2011 because of the inferred global decline due to

53 directed gill-plate fisheries and their inferred slow life histories (Marshall et al. 2011a; Marshall

54 et al. 2011b). Moreover, recognizing this threat, Brazil, Colombia and Ecuador successfully

55 proposed Manta spp. for inclusion in Appendix II of the Convention on International Trade in

56 Endangered Species of Wild Fauna and Flora (CITES). These listings will come into force on

57 14th September 2014, by which time their international trade will only be allowed if: (1)

58 specimens were legally sourced, and (2) the export is not detrimental to wild populations of the species (a non-detriment finding, NDF) (Mundy-Taylor \& Crook 2013; Vincent et al. 2013).

60 Non-detriment findings rely on the ability to assess the sustainability of removals of individuals

61 for the international trade from national populations. One of the principal challenges of assessing

62 sustainability is that there is often a high degree of uncertainty in the population biology of

63 species, and the pattern and rate of exploitation (Ludwig et al. 1993). However, decisions on the

64 sustainability of fisheries and trade often have to be made without the benefit of sufficient

65 information. Recent advances have made it possible to account for sources of uncertainty and this

66 is increasingly an important part of the decision-making process in fisheries management and

67 conservation (Baker \& Clapham 2004; Magnusson et al. 2012; Peterman 2004).

68 One approach to dealing with uncertainty in life histories is to draw upon life history tradeoff 69 rules that constrain the range of plausible trait values (Beverton \& Holt 1959; Law 1979). There

70 are fundamental constraints to the acquisition, allocation and metabolism of energy resulting in a

71 narrow set of rules of life (Dulvy \& Forrest 2010; Jennings \& Dulvy 2008). These rules can be

72 used to choose a plausible range of life history traits, which when combined with simple methods

73 to propagate the uncertainty in the true trait value, can be used to provide powerful insights into

74 demography and fisheries sustainability (Beddington \& Kirkwood 2005). Recent work using a

75 simple life history model suggests manta rays are intrinsically sensitive and have low capacity to

76 rebound from even low levels of fishing mortality (Ward-Paige et al. 2013). 
77 Here, we examine the potential risk to manta ray populations from fishing to supply the dried gill 78 plate trade. Specifically, we calculate the maximum intrinsic rate of population increase $\left(r_{\max }\right)$ of 79 manta rays, and compare their demography to other sharks and rays. Our model and approach 80 provides a demographic basis for evaluating the sustainability, or otherwise, of manta fisheries, in

81 the face of considerable uncertainty in their life history.

\section{Materials and methods}

83 We first outline the Euler-Lotka life history model and the three key parameters required to 84 estimate the maximum rate of population increase $\left(r_{\max }\right)$ : the annual rate of production of female offspring ( $\tilde{\alpha} \dot{i}$, age at maturity $\left(\alpha_{\text {mat }}\right)$, and the instantaneous natural mortality rate $(M)$. Second,

86 we describe plausible ranges for each of those parameters for a generic manta ray life history.

87 Third, we use a Monte Carlo procedure to propagate the uncertainty these three life history 88 parameters through the Euler-Lotka model to calculate a distribution of the plausible range of 89 manta ray maximum rate of population increase $r_{\max }$. Finally, we compare the demography of the manta ray to the life histories and demography of 106 other sharks and rays.

91 We chose to estimate the extinction risk of manta rays by calculating the maximum rate of population increase using a variant of the Euler-Lotka model (García et al. 2008; Hutchings et al.

93 2012). This is one of the oldest and simplest life history models and is founded on the principle 94 that a breeding female only has to produce one mature female in her lifetime to ensure a stable 95 population size (Charnov \& Schaffer 1973; Charnov \& Zuo 2011; Myers \& Mertz 1998;

96 Simpfendorfer 2005):

$$
\tilde{\alpha}=\left(e^{r_{\max }}\right)^{\alpha_{\operatorname{mat}}}-p\left(e^{r_{\max }}\right)^{\alpha_{\operatorname{mat}}-1},
$$

97 where $\tilde{\alpha}$ is the annual rate of production of female offspring. Here we calculated $\tilde{\alpha}$ as $l / i$

$98 * 0.5$, where is $l$ litter size and $i$ is breeding interval, corrected for sex ratio i.e. 0.5$). \alpha_{m a t}$ is age at 99 maturity, and $p$ is the adult survival rate, where $p=e^{-M}$, where $M$ is the instantaneous natural 100 annual mortality rate $\mathrm{yr}^{-1}$. While local aggregations of manta rays may be sex-biased we assume 101 an even sex ratio at the, wider, species level. The simple elegance of the model is that it requires 
102 only estimates of three biological parameters: annual reproductive output ( $\tilde{\alpha}$ ), age at maturity

$103\left(\alpha_{\text {mat }}\right)$, and natural mortality $(M)$. Two of these parameters are highly uncertain $\left(\tilde{\alpha}\right.$ and $\left.\alpha_{\text {mat }}\right)$ and

104 the other $(M)$ is estimated indirectly, which can also result in uncertainty. Hence, we aim to

105 estimate a range of $r_{\max }$ to encompass the widest range of life histories that are plausible for manta 106 rays and hence would encompass the true parameter values.

107 The existence of more than one species of manta ray was only recently recognized (Marshall et 108 al. 2009); furthermore, with the geographic overlap and in the absence of sufficient evidence to 109 differentiate the life history traits required by the model we thought it most defensible to evaluate 110 a generic manta ray life history.

111 Annual reproductive output ( $\tilde{\alpha}$ ). One pup is produced per litter (rarely two) and gestation 112 period is approximately one year (366-374 days in the Okinawa aquarium) (Couturier et al. 113 2012). This suggests at least an annual breeding interval, but there may also be a chance of 114 skipped breeding or multiannual reproductive cycles. There is evidence for a biennial cycle where 1151 pup is produced every two years (Couturier et al. 2012; Marshall \& Bennett 2010). Even more 116 extreme example is the recent discovery of a complete absence of pregnant females for four years 117 in the Maldive Islands, following three biennial cycles, which could be interpreted as one pup 118 every five years (personal communication; Guy Stevens, Environment Department, University of 119 York, UK). Similar patterns of skipped reproduction have been noted in Japanese waters (Tom 120 Kashiwagi, School of Biomedical Sciences, University of Queensland, Queensland 4072, 121 Australia). It is worth noting that extended periods of 'non-pregnancy' may be an artifact of 122 occasional sightings and / or poor viewing angles (M. B. Bennett, University of Queensland, 123 Australia, pers. comm.). As is typical in demographic modeling we assume an even sex ratio. 124 Under these assumptions a plausible range would be an annual reproductive output averaging 1250.25 to 0.5 female pups per year, but we considered extremes out to an annual reproductive 126 output 0.1 ( 1 female pup every five years). Because of the simple tractable nature of our 127 modeling approach, we did not have the opportunity to consider juvenile mortality. However, 128 juvenile survival may not be of overriding importance for overall population growth rate, because 129 they are likely to have low mortality and contribute relatively little to population growth rate 130 compared to sub-adults (Heppell et al. 1999). We expect manta pups to have low mortality due to 
131 their extremely large size in comparison to other sharks and rays. Mortality patterns are strongly

132 size-dependent in the ocean and hence larger individuals are likely to have much higher survival 133 rates (Charnov et al. 2012; Gislason et al. 2010; Pope et al. 1994). Manta offspring are some of

134 the largest offspring of any ectotherm in the ocean. The size of birth of manta pups is $130-150 \mathrm{~cm}$

135 disc width, considering the maximum linear dimension this is one of the largest of any

136 elasmobranch. The maximum linear dimensions of offspring sizes of 274 elasmobranchs ranged

137 from $6.8 \mathrm{~cm}$ in Cuban pygmy skate (Fenestraja cubensis) to $175 \mathrm{~cm}$ in the basking shark

138 (Cetorhinus maximus), and the size at birth disc width of a manta ray of 130-150 cm lies in the

139 upper $95^{\text {th }}$ percentile of the distribution of maximum linear dimension of size at birth or hatch of 140 these elasmobranchs (Cortés 2000; Goodwin et al. 2002; Jennings et al. 2008). As survival

141 information becomes available, future models that account for age and stage-specific mortality

142 are likely to provide more nuanced insights into manta ray demography.

143 Age at maturity $\left(\alpha_{m a t}\right)$. Male reef manta rays (M. alfredi) mature at 3-6 years in Hawaii and 144 female maturity is subject to considerable debate, and for our purposes is inferred to be 8-10 145 years (Marshall et al. 2011b).

146 Natural mortality $(M)$ can be estimated indirectly from the von Bertalanffy growth coefficient

$147(k)$ or can be assumed to be the reciprocal of lifespan, 1/maximum age (Charnov et al. 2012;

148 Dulvy et al. 2004; Pauly 2002). Here we draw inferences from both approaches.

149 There is no growth curve available for manta rays, however we can draw some inference as to the 150 plausible range because fish growth parameters are narrowly constrained and highly correlated 151 because of fundamental life history tradeoffs (Charnov et al. 2012). The rate of somatic growth 152 (as indexed by the von Bertalanffy growth coefficient, $k$ ) is negatively-related to the asymptotic

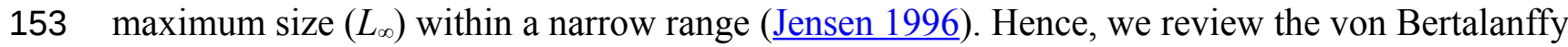
154 growth curves of larger tropical batoids $(>1 \mathrm{~m})$ to guide the choice of a plausible range of $k$ for 155 manta rays. The available growth rates for species with similar lifestyles, tropical and subtropical 156 myliobatoid rays (Table 1) and the tropical planktivorous whale shark, reveals that most $k$ values 157 lie between $0.009 \mathrm{yr}^{-1}$ and $0.28 \mathrm{yr}^{-1}$ (Table 1). It might be expected manta rays would have $k$ 158 values toward the lower end of this range because they reach a considerably larger size than most 159 of these myliobatoid rays. While known from temperate regions, they are typically found in 
160

161

162

163

164

165

166

167

168

169

170

171

172

173

174

175

176

177

178

179

180

181

182

183

184

185

186

187

188

warm tropical and subtropical water. They are planktivores and hence can access a much larger

food resource base and higher growth might be expected at high temperatures. There is some evidence that planktivores grow quickly because their feeding mode is more energetically profitable when individuals (and their gape) reach a larger size. Comparisons to whale shark and the slower growing myliobatoid rays would suggest manta $k$ values around 0.03-0.04 $\mathrm{yr}^{-1}$ (Wintner 2000).

The maximum age of manta rays can be inferred from the longest period of resightings of individuals through photo identification projects (Town et al. 2013). In Hawai'i one female has been continuously resighted since 1979, providing a minimum estimate of longevity of the

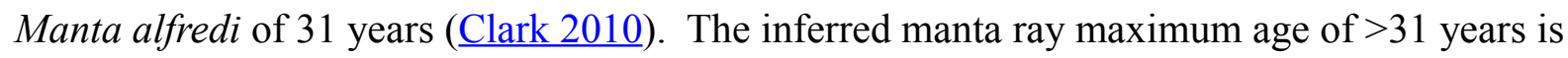
considerably higher than the 19 to 25 years for Aetobatis flagellum, Myliobatis californicus and Rhinoptera bonasus, so a more plausible range for $k$ might be 0.05-0.1 $\mathrm{yr}^{-1}$. Life history invariants can be used to estimate mortality from growth rate, assuming an $M / k$ ratio of 0.4 which is more typical for elasmobranch fishes than the higher ratio of $M / k=1.5$ observed in teleost fishes and reptiles (Frisk et al. 2001). For a range of $k$ of $0.03-0.1$, then $M$ is between 0.012 and $0.04 \mathrm{yr}^{-1}$.

We model parameters encompassing the following ranges: $k=0.03-0.1, M=0.012$ to 0.04 , age at maturity $=8-10$ years and an annual reproductive rate of 0.25 to 0.5 female pups per year. To propagate the uncertainty inherent in these parameter ranges, we drew 10,000 values of each parameter from a random uniform distribution bounded by the plausible range of each. While life history traits are typically distributed around a mean value in a Gaussian manner, we choose a more conservative uniform distribution to explore the full range of parameter space. Maximum intrinsic population growth rate was calculated for the 10,000 triplets of $\quad \tilde{\alpha}, \alpha_{\text {mat }}$ and $M$ by iteratively solving for $r_{\max }$ using the n lminb optimization function in R statistical software version 2.15 ( $\underline{\mathrm{R} \text { Core Team 2013)}}$.

We compared the manta ray $r_{\max }$ to all available estimates $(n=106)$, comprising 105 published estimates for chondrichthyans (García et al. 2008), to which we added the filter-feeding CITESlisted basking shark (Cetorhinus maximus) which has an $M$ of 0.024 (based on a growth coefficient $k$ of 0.067 ), age at maturity of 10, and an annual reproductive output of 1.5 females per litter every two years (assuming an 18 month pregnancy) (Pauly 2002). For plotting, we 
189

190

191

192

193

194

195

196

197

198

199

200

201

202

203

204

205

206

207

208

209

210

211

212

213

extracted all maximum sizes as the total length in centimeters, except for Myliobatiformes and Chimaeriformes for which we used disc width and fork length, respectively (García et al. 2008; Pauly 2002). There is wide geographic variation in maximum disc width and many M. alfredi individuals average around $400 \mathrm{~cm}$ increasing to $490 \mathrm{~cm} \mathrm{DW} \mathrm{cm} \mathrm{(Marshall} \mathrm{et} \mathrm{al.} \mathrm{2011c).} \mathrm{The}$ giant manta ray consistently reaches a maximum size of over $700 \mathrm{~cm} \mathrm{DW}$ with anecdotal reports of up to $910 \mathrm{~cm} \mathrm{DW}$ (Marshall et al. 2009). Here, for graphical purposes we assumed a maximum size of $600 \mathrm{~cm}$ DW.

\section{Results}

Assuming that the range of life histories explored encompasses our current knowledge, then the median maximum intrinsic rate of population increase $r_{\max }$ for manta ray is $0.116(95 \%$ Confidence Interval $=0.089-0.139$, Figure $2 a$ ). The lowest $r_{\max }$ value of 0.079 corresponds to an annual reproductive output, $\tilde{\alpha}=0.25, \alpha_{\text {mat }}=10$ years, and natural mortality, $M=0.04$, and the highest $r_{\max }$ of 0.15 corresponding to $\tilde{\alpha}=0.5, \alpha_{\text {mat }}=8$ years, and $M=0.012$.

The $r_{\max }$ decreases considerably when annual reproductive output is lower. The $r_{\max }$ is most sensitive to annual reproductive output $\tilde{\alpha}$ compared to the age at maturation $\alpha_{\text {mat }}$, note the difference between each $\tilde{\alpha}$ is greater than among growth rates or ages of maturation (Figure $2 b)$. The sensitivity to annual reproductive output $\tilde{\alpha}$ relative to age at maturation $\alpha_{\text {mat }}$ becomes increasingly important when annual reproductive output is low (Figure $2 b$ ). There is a positive relationship between growth (and hence mortality) and $r_{\max }$ across species (Figure $3 a$ ), and larger species have lower $r_{\max }$ (Figure $3 b$ ).

Of the 106 species for which we could calculate the maximum intrinsic rate of population increase, the manta ray had one of the lowest $r_{\max }$ values $(0.116)$. The $r_{\max }$ of deepwater sharks $(n=$ 14) is significantly lower than for continental shelf and oceanic pelagic species, as revealed by García et al. (2008). Aside from the deepwater sharks which are all intrinsically sensitive to

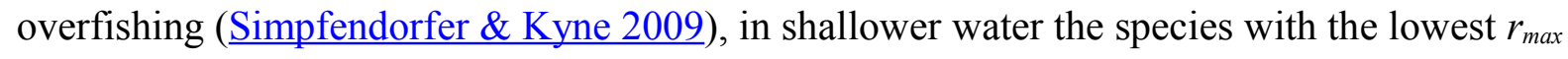


214 were the temperate basking shark (Cetorhinus maximus) $r_{\max }=0.109$, followed by the manta ray $215\left(r_{\max }=0.114\right)$.

216 We compared the maximum population growth rate $r_{\max }$ as calculated from the modified Euler-

217 Lotka models and the population growth rate $r$ (which equals $\ln [\lambda]$ ) as calculated from age-

218 structured models (Cortés 2002). We found both measure of population growth significantly

219 related, but the slope of the relationship was 0.26 ( \pm 0.09 standard error) suggesting $r_{\max }$ is

220 typically four times greater than $r\left(F_{1,27}=8.09, p=0.008\right.$, adjusted $\left.r^{2}=0.2\right)$. Hence, in assessing

221 the productivity of species against the criteria of Food and Agriculture Organization of the United 222 Nations (Musick 1998), it might be more precautionary to estimate $r$ as $r_{\max } / 4=0.029(95 \% \mathrm{CI}=$ $2230.022-0.35)$, and hence manta ray has "very low" productivity $(<0.05)$.

\section{Discussion}

225 we show how life history theory can be used to guide the estimation of an important demographic 226 parameter - the maximum intrinsic rate of population increase $r_{\max }$ - and likely sustainability of 227 even the most difficult-to-study marine animals. Manta rays are data poor but compared to many 228 other chondrichthyans they are still relatively data rich. Of the 1100+ known species, manta rays are among the 106 species for which we can calculate $r_{\max }$. Nevertheless, the paucity of life history data for manta rays is very typical of the many data-poor fisheries of the world, particularly in the tropics. But the absence of data should not preclude or delay management. Our analysis shows that manta rays have one of the lowest maximum intrinsic rates of population increase of any of the chondrichthyans studied to date. Our approach is designed not to estimate the one true value of the maximum intrinsic population growth rate but to calculate these values while understanding the sensitivity to the input parameters and accounting for uncertainty in those values. Despite some uncertainty in life history traits, the plausible range of manta ray $r_{\max }$ estimates is narrow (Figure 2), because life history tradeoffs between maximum asymptotic size and the growth rate narrow the parameter space. It is likely that the range is narrower than we show because we could not account for the covariance of life history traits, if we were able to do so this would further narrow the plausible range of manta ray $r_{\max }$ estimates.

241 We find that the maximum rate of population increase is slightly higher than a recent estimate of 242 the intrinsic rate of population increase, $r=0.042-0.05$ (Ward-Paige et al. 2013), compared to our 243 median $r_{\max }=0.11$. The range of parameters we used encompassed those of Ward-Paige et al. 
244 (2013) and suggest the difference in $r$ versus $r_{\max }$ may be due to differences in the method used to

245 estimate natural mortality and that the rebound potential method consistently provides lower

246 growth rate. We used an elasmobranch-specific mortality estimator (Frisk et al. 2001), whereas

247 the other used an estimator based on fishes, molluscs and whales (ㅎoenig 1983). A more puzzling

248 issue is why our approach reveals that manta rays have one of the lowest $r_{\max }$ of any

249 chondrichthyan, whereas the other suggests manta rays may have an intermediate $r$ (Ward-Paige

250 et al. 2013). This issue is beyond the scope of this paper, and requires a simulation-based

251 performance comparison of these kinds of models. While close, the difference in demographic

252 estimates underscores the need for a better understanding of such rule-of-thumb mortality

253 estimators and a comparison of the performance of different variants of simple scalar

254 unstructured demographic models, such as the Euler-Lotka model, the rebound potential model,

255 and Pope's Fjeopardy model (Pope et al. 2000; Simpfendorfer 2005; Smith et al. 1998).

256 Without the opportunity to consider juvenile survival rate our estimates of $r_{\max }$ may be slightly too

257 high. We implicitly assume that juveniles have the same survival rate as adults. However, a more

258 realistic assumption might be to assume that juvenile survival rate approaches adult survival rate

259 as described by survival to adulthood raised to the power of the age of maturity. Such an

260 approach to juvenile survival would result in smaller $r_{\max }$ values than we present here (E. L.

261 Charnov, University of New Mexico, pers. comm.).

262 Manta rays have very low productivities and even a low fishing mortality $\left(F_{\text {extinct }}\right)$ would drive

263 them to extinction. The manta ray $r_{\max }=0.114$ falls within the 'low' category of the productivity

264 classification used by CITES ( $\underline{0.05}$ to 0.15, Musick 1999). However, we highlight that the

265 maximum population growth rate $r_{\max }$ reported here is typically four times greater than the

266 intrinsic population growth rate $r$ as derived from age-structured models (e.g. Cortés 2002).

267 Hence,manta rays are more likely to be classified as having "very low" productivity $(<0.05)$

268 (FAO 2013). With additional field data, there is scope to refine and reduce the uncertainty in the

269 estimates of manta ray productivity.

270 One might object to the calculation of $r_{\max }$ given such great uncertainty in basic life history of

271 these data-poor species. However, the pragmatic reality is that we do not have the luxury of

272 waiting for more data to become available. And indeed increasing effort is being paid to 
273 understanding safe biological limits for the exploitation of target and bycatch species (Dulvy et

274 al. 2004; Pardo et al. 2012). At the most recent $16^{\text {th }}$ Conference of the Parties of the Convention

275 on the International Trade in Endangered Species both species of manta ray were listed on

276 Appendix II, which includes, "species that are not necessarily now threatened with extinction but

277 that may become so unless trade is closely controlled". Under this regulation Appendix II species

278 can only be traded subject to three conditions, two of which pertain to the legality of capture and

279 welfare (of live transported species), and the third relates to the sustainability (or otherwise) of

280 trade - the so called non-detriment finding (Vincent et al. 2013). A non-detriment finding

281 confirms that the trade of specimens will not be detrimental to wild populations of the species. A

282 key condition of the CITES listings of both manta rays has been a delay by 18 months until $14^{\text {th }}$

283 September 2014 (CITES 2013). By this date, any nation, that is party to the CITES, wishing to

284 trade manta ray gill plates (or other products) needs to develop methods for assessing that

285 proposed trade is sustainable and not detrimental to wild populations. There is very little time in

286 which to gather new data and hence our simple modeling demographic model, constrained by life

287 history tradeoffs and accounting for and propagating biological uncertainty, provides a much-

288 needed first step toward developing methods to support the development of methods to assess the sustainability of exploitation and international trade.

290 Our analysis reveals that a key parameter to estimate in future field studies are the growth rate $k$

291 from a von Bertalanffy growth curve, fitted appropriately to size-at-age data (Pardo et al. 2013;

292 Smart et al. 2013; Thorson \& Simpfendorfer 2009). Hopefully, the growth rate $k$ can be estimated

293 for manta rays, as has been done for other smaller tropical myliobatoids (Table 1). However,

294 there is a real possibility that annuli may not be recoverable from manta rays because mobulid

295 vertebrate tend to be poorly calcified (W.,D. Oregon State University, Corvalis, USA, pers.

296 comm.). Hence, resighting programmes may be the most pragmatic method of estimating a

297 growth curve (Town et al. 2013). As we have shown, natural mortality rate depends heavily on $k$

298 and the ratio of $M / k$, which is around 0.4 for elasmobranchs (Frisk et al. 2001). If it is not

299 possible to estimate a growth curve for manta rays in the near future then demographic modeling

300 will be heavily reliant on our understanding of: (1) the overall pattern of maximum size $\left(L_{\square}\right)$ and

301 growth rate $(k)$ in elasmobranchs, and especially tropical and subtropical batoids, and (2) the $M / k$

302 ratio. Future work should concentrate on understanding why the elasmobranch $M / k$ ratio is

303 around 0.4 , by comparison the teleost and reptile $M / k$ ratio is around 1.5 (Charnov et al. 1993).

304 Why is this so? This ratio has a profound influence on the estimate of population growth rate and 
305 the sustainability of species, and hence understanding the life histories, ecological and

306 environmental correlates of the $M / k$ ratio can only improve the predictive power of these simple

307 demographic models.

308 Other parameters that strongly influence the maximum intrinsic rate of population increase are

309 the age at maturation and the annual reproductive rate. These parameters very poorly understood

310 (Marshall \& Bennett 2010). The manta ray annual reproductive rate estimates of one pup per year

311 are based on aquarium-held specimens under relatively ideal conditions, and hence these

312 estimates are likely to be optimistic. There is unpublished evidence suggesting that annual

313 reproductive rates may be much, much lower and variable among and within individuals. The

314 proportion of pregnant females returning to long-term (6-8 years) study sites in the Maldives

315 previously suggested a biennial reproductive mode, but in recent years no pregnant females have

316 returned (G. Stevens, Manta Ray of Hope, UK, pers. comm.). The absence of returning pregnant

317 females may indicate a spatial shift of returning females, but also may hint at much lower and

318 more variable annual rates of reproductive output than we have modeled here. We recommend

319 that the demographic rates of manta rays be revised as more details of the temporal and

320 geographic variability in reproductive output come to light. The emerging observations of year-

321 to-year variation in individual reproductive output may lead to variance in year-to-year

322 population growth rate which can only serve to depress the long-term population growth rate

323 further elevating extinction risk (Hutchings 1999). And indeed such observations caution us to

324 initiate and undertake local analyses of population structure and reproductive activity and to

325 incorporate local variations into local demographic models and assessments contribution to

326 CITES Non-Detriment Findings. Of course the greatest uncertainty, that we have entirely

327 overlooked, is that future demographic estimates would benefit greatly from species-specific

328 estimates of the key life history parameters: growth rate $k$, annual reproductive rate and age at

329 maturity.

330 Notwithstanding the current uncertainty in the life history of manta rays, given their very low

331 productivity coupled with small localized populations and predictable seasonal aggregations, the

332 unregulated targeting of local Manta populations for their high-value gill plates is unlikely to be

333 sustainable. The largest targeted fisheries and highest mortality occurs in Indonesia, Sri Lanka,

334 India, Peru and Mozambique and these countries have little fisheries monitoring, regulation or

335 effective enforcement. The time to local extinction depends on the size of the population and the 
336 rate of fishing mortality. The very low productivity of manta rays mean that even a moderate

337 level of fishing mortality of $F=0.2$ (survival $=0.81$ ) would reduce a small population of 100

338 individuals to fewer than 10 within less than a generation span (11 years). The key challenge this

339 poses is that it leaves little time to mount an effective conservation management response. These

340 serial depletion fisheries are operated by low-income subsistence coastal fishers, often against a

341 backdrop of declining fish stocks. For such fishers the international market demand for valuable

342 Manta and mobulid ray gill plates is likely to provide a desirable income. Such fisheries tend to

343 be unregulated and even if there are protections these are difficult to enforce, which underscores

344 the importance of international trade regulation.

\section{Acknowledgements}

346 We thank Thomasina Oldfield and Martin Jenkins for motivating this study. This work was

347 originally submitted as a working paper to the Fourth United Nations Food and Agriculture

348 Organization Expert Advisory Panel which met from 3-8 ${ }^{\text {th }}$ December 2012. We thank María José

349 Juan Jordá and Lucy R. Harrison for constructive comments and Tracy Saxby, Integration and

350 Application Network, University of Maryland Center for Environmental Science

351 (ian.umces.edu/imagelibrary/) for providing the images. Finally, we thank John Bruno, Mike

352 Bennett and Alastair Dove for their insightful comments and critique. Thanks are also due to Eric

353 Charnov who provided unsolicited and welcome comments on the PeerJ Preprint version. 
354

355

356

357

358

359

360

361

362

363

364

365

366

367

368

369

370

371

372

373

374

375

376

377

378

\section{References}

Anderson SC, Flemming JM, Watson R, and Lotze HK. 2011. Serial exploitation of global sea cucumber fisheries. Fish and Fisheries 12:317-339.

Baker CS, and Clapham PJ. 2004. Modelling the past and future of whales and whaling. Trends In Ecology \& Evolution 19:365-371.

Beddington JR, and Kirkwood GP. 2005. The estimation of potential yield and stock status using lifehistory parameters. Philosophical Transactions of the Royal Society of London, Biological Sciences 360:163-170.

Berkes F, Hughes TP, Steneck RS, Wilson JA, Bellwood DR, Crona B, Folke C, Gunderson LH, Leslie HM, Norberg J, Nyström M, Olsson P, Österblom H, Scheffer M, and Worm B. 2006. Globalization, roving bandits, and marine resources. Science 311:1557-1558.

Beverton RJH, and Holt SJ. 1959. A review of the life-spans and mortality rates of fish in nature and their relationship to growth and other physiological characteristics. Ciba Foundation Colloquia on Aging 5:142-180.

Charnov EL, Berrigan D, and Shine R. 1993. The $M / k$ ratio is the same for fish and reptiles. American Naturalist 142:707-711.

Charnov EL, Gislason H, and Pope JG. 2012. Evolutionary assembly rules for fish life histories. Fish and Fisheries 14:213-224.

Charnov EL, and Schaffer WM. 1973. Life-History Consequences of Natural-Selection - Coles Result Revisited. American Naturalist 107:791-793.

Charnov EL, and Zuo WY. 2011. Human hunting mortality threshold rules for extinction in mammals (and fish). Evolutionary Ecology Research 13:431-437.

CITES. 2007. Interpretation and implementation of the Convention Species trade and conservation issues Sharks. The Hague, Netherlands: Convention on the International Trade in Endangered Species. p 62. 
379

380

381

382

383

384

385

386

387

388

389

390

391

392

393

394

395

396

397

398

399

400

401

402

403

404

405

CITES. 2013. Amendments to appendices I and II of the Convention adopted by the Conference of the Parties at its 16th meeting, Bangkok (Thailand), 3-14 March 2013. Geneva, Switzerland: Convention on the International Trade in Endagnered Species. $\mathrm{p} 8$.

Clark T. 2010. Abundance, home range, and movement patterns of manta rays (Manta alfredi, M. birostris) in Hawai'i PhD. University of Hawai'i, Manoa.

Clarke SC. 2004. Understanding pressures on fishery resources through trade statistics: a pilot study of four products in the Chinese dried seafood market. Fish \& Fisheries 5:53-74.

Clarke SC, McAllister MK, Milner-Gulland EJ, Kirkwood GP, Michielsens CGJ, Agnew DJ, Pikitch EK, Nakano H, and Shivji MS. 2006. Global estimates of shark catches using trade records from commercial markets. Ecology Letters 9:1115-1126.

Cortés E. 2000. Life history patterns and correlations in sharks. Reviews in Fisheries Science 8:299-344.

Cortés E. 2002. Incorporating uncertainty into demographic modelling: application to shark populations and their conservation. Conservation Biology 18:1048-1062.

Couturier LIE, Marshall AD, Jaine FRA, Kashiwagi T, Pierce SJ, Townsend KA, Weeks SJ, Bennett MB, and Richardson AJ. 2012. Biology, ecology and conservation of the Mobulidae. Journal Of Fish Biology 80:1075-1119.

Cuevas-Zimbrón E, Sosa-Nishizaki O, Pérez-Jiménez JC, and O'Sullivan JB. 2012. An analysis of the feasibility of using caudal vertebrae for ageing the spinetail devilray, Mobula japanica (Müller and Henle, 1841). Environmental Biology Of Fishes 96:907-914.

Dulvy NK, Ellis JR, Goodwin NB, Grant A, Reynolds JD, and Jennings S. 2004. Methods of assessing extinction risk in marine fishes. Fish and Fisheries 5:255-275.

Dulvy NK, and Forrest RE. 2010. Life histories, population dynamics, and extinction risks in chondrichthyans. In: Carrier JC, Musick JA, and Heithaus MR, eds. Sharks and Their Relatives II: Biodiversity, Adaptive Physiology, and Conservation. Boca Raton: CRC Press, 635-676.

Dulvy NK, Fowler SL, Musick JA, Cavanagh RD, Kyne PM, Harrison LR, Carlson JK, Davisdson LNK, Fordham S, Francis MP, Pollock CM, Simpfendorfer CA, Burgess GH, Carpenter KE, Compagno LVJ, Ebert DA, Gibson C, Heupel MR, Livingstone SR, Sanciangco JC, Stevens JD, Valenti S, 
406

407

408

409

410

411

412

413

414

415

416

417

418

419

420

421

422

423

424

425

426

427

428

429

430

and White WT. 2014. Extinction risk and conservation of the world's sharks and rays. eLIFE 3:e00590.

FAO. 2013. Fourth FAO Expert Advisory Panel for the Assessment of Proposals to Amend Appendices I and II of CITES Concerning Commercially-exploited Aquatic Species. Rome, Italy: Food and Agriculture Organization of the United Nations. p 169.

Foster SJ, and Vincent ACJ. 2004. Life history and ecology of seahorses: implications for conservation and management. Journal Of Fish Biology 65:1-61.

Frisk MG, Miller TJ, and Fogarty MJ. 2001. Estimation and analysis of biological parameters in elasmobranch fishes: a comparative life history study. Canadian Journal Of Fisheries and Aquatic Sciences 58:969-981.

García VB, Lucifora LO, and Myers RA. 2008. The importance of habitat and life history to extinction risk in sharks, skates, rays and chimaeras. Proceedings of the Royal Society of London, B 275:8389.

Gislason H, Daan N, Rice JC, and Pope JG. 2010. Size, growth, temperature and the natural mortality of marine fish. Fish and Fisheries 11:149-158.

Goodwin NB, Dulvy NK, and Reynolds JD. 2002. Life history correlates of the evolution of live-bearing in fishes. Philosophical Transactions of the Royal Society of London, B 356:259-267.

Heinrichs S, O'Malley M, Medd H, and Hilton P. 2011. Manta Ray of Hope: Global Threat to Manta and Mobula Rays. Available at http://www.mantarayofhope.com2011).

Heppell SS, Crowder LB, and Menzel TR. 1999. Life table analysis of long-lived marine species with implications for conservation and management. In: Musick JA, ed. Life in the slow lane: ecology and conservation of long-lived marine animals. Bethesda, Maryland: American Fisheries Society, $137-147$.

Hoenig JM. 1983. Empirical use of longevity data to estimate mortality rates. Fisheries Bulletin 81:898903. 
431 Hutchings JA. 1999. Influence of growth and survival costs of reproduction on Atlantic cod, Gadus

432

433

434

435

436

437

438

439

440

441

442

443

444

445

446

447

448

449

450

451

452

453

454

455

456

morhua, population growth rate. Canadian Journal of Fisheries and Aquatic Science 56:16121623.

Hutchings JA, Myers RA, Garcia VB, Lucifora LO, and Kuparinen A. 2012. Life-history correlates of extinction risk and recovery potential. Ecological Applications 22:1061-1067.

IUCN/TRAFFIC. 2013. IUCN/TRAFFIC Analyses of the Proposals for CITES CoP15. Available at http://www.traffic.org/cop16-table/.

Jennings S, and Dulvy NK. 2008. Beverton and Holt's insights into life history theory: influence, application and future use. In: Payne AI, Cotter AJR, and Potter ECE, eds. Advances in fisheries Science: 50 years on from Beverton and Holt. Oxford: Blackwell Publishing, 434-450.

Jennings S, Mélin F, Blanchard JL, Forster RM, Dulvy NK, and Wilson RW. 2008. Global-scale predictions of community and ecosystem properties from simple ecological theory. Proceedings of the Royal Society B: Biological Sciences 275:1375-1383.

Jensen AL. 1996. Beverton and Holt life history invariants result from optimal trade-off of reproduction and survival. Canadian Journal Of Fisheries and Aquatic Sciences 53:820-822.

Law R. 1979. Ecological determinants in the evolution of life histories. In: Anderson RM, Turner BD, and Taylor LR, eds. Population dynamics. Oxford: Blackwell Scientific Publications, 81-103.

Lenzen M, Moran D, Kanemoto K, Foran B, Lobefaro L, and Geschke A. 2012. International trade drives biodiversity threats in developing nations. Nature 486:109-112.

Ludwig D, Hilborn R, and Walters C. 1993. Uncertainty, resource exploitation, and conservation - lessons from history. Science 260:17-36.

Magnusson A, Punt AE, and Hilborn R. 2012. Measuring uncertainty in fisheries stock assessment: the delta method, bootstrap, and MCMC. Fish and Fisheries:no-no.

Marshall A, Bennett MB, Kodja G, Hinojosa-Alvarez S, Galvan-Magana F, Harding M, Stevens G, and Kashiwagi T. 2011a. Manta birostris. Available at http://www.iucnredlist.org/details/198921/0 (accessed 04 December 2012 2012). 
457

458

459

460

461

462

463

464

465

466

467

468

469

470

471

472

473

474

475

476

477

478

479

480

481

482

Marshall A, Kashiwagi T, Bennett MB, Deakos M, Stevens G, McGregor F, Clark T, Ishihara H, and Sato K. 2011b. Manta alfredi. Available at http://www.iucnredlist.org/details/195459/0 (accessed 04 December 2012 2012).

Marshall AD, and Bennett MB. 2010. Reproductive ecology of the reef manta ray Manta alfredi in southern Mozambique. Journal Of Fish Biology 77:169-190.

Marshall AD, Compagno LJV, and Bennett MB. 2009. Redescription of the genus Manta with resurrection of Manta alfredi (Krefft, 1868) (Chondrichthyes; Myliobatoidei; Mobulidae). Zootaxa 2301:1-28.

Marshall AD, Dudgeon CL, and Bennett MB. 2011c. Size and structure of a photographically identified population of manta rays Manta alfredi in southern Mozambique. Marine Biology 158:1111-1124.

Martin LK, and Cailliet GM. 1988. Aspects of reproduction of the bat ray Myliobatis california, in Central California. Copeia:754-762.

Mundy-Taylor V, and Crook V. 2013. Into The Deep: Implementing CITES Measures for Commerciallyvaluable Sharks and Manta Rays. Cambridge: TRAFFIC. p 106.

Musick JA. 1998. Endangered marine fishes: criteria and identification of North American stocks at risk. Fisheries 2:28-30.

Musick JA. 1999. Criteria to define extinction risk in marine fishes. Fisheries 24:6-14.

Myers RA, and Mertz G. 1998. The limits of exploitation: A precautionary approach. Ecological Applications 8:S165-S169.

Neer JA, and Thompson BA. 2005. Life history of the cownose ray, Rhinoptera bonasus, in the northern Gulf of Mexico, with comments on geographic variability in life history traits. Environmental Biology Of Fishes 73:321-331.

O’Malley MP, Lee-Brooks K, and Medd HB. 2013. The global economic impact of manta ray watching tourism. PLoS ONE 8:e65051.

Pardo S, Cooper AB, and Dulvy NK. 2012. Critical review and analysis of existing risk-based techniques for determining sustainable mortality levels of bycatch species. DFO Can Sci Advis Sec Res Doc. Ottawa: Fisheries and Oceans Canada. p v +30 . 
483 Pardo S, Cooper AB, and Dulvy NK. 2013. Avoiding fishy growth curves. Methods in Ecology and

484

485

486

487

488

489

490

491

492

493

494

495

496

497

498

499

500

501

502

503

504

505

506

507

508 Evolution 4:353-360.

Pauly D. 2002. Growth and mortality of the Basking Shark Cetorhinus maximus and their implications for management of Whale Sharks Rhincodon typus. In: Fowler SL, Reed TM, and Dipper FA, eds. Proceedings of the international seminar and workshop, Sabah, Malaysia, July 1997. Gland, Switzerland and Cambridge, UK: IUCN Species Survival Commission Shark Specialist Group, 199-208.

Peterman RM. 2004. Possible solutions to some challenges facing fisheries scientists and managers. ICES Journal Of Marine Science 61:1331-1343.

Phillis CC, O’Regan SM, Green SJ, Bruce JEB, Anderson SC, Linton JN, and Favaro B. 2013. Multiple pathways to conservation success. Conservation Letters 6:98-106.

Pope JG, MacDonald DS, Daan N, Reynolds JD, and Jennings S. 2000. Gauging the vulnerability of nontarget species to fishing. ICES Journal Of Marine Science 57:689-696.

Pope JG, Shepherd JG, and Webb J. 1994. Successful surf-riding on size spectra: the secret of survival in the sea. Philosophical Transactions of the Royal Society of London, B 343:41-49.

R Core Team. 2013. R: A language and environment for statistical computing. Vienna, Austria: R Foundation for Statistical Computing.

Sadovy Y, and Cheung WL. 2003. Near extinction of a highly fecund fish: the one that nearly got away. Fish and Fisheries 4:86-99.

Sadovy Y, and Vincent AJ. 2002. Ecological issues and the trades in live reef fishes. In: Sale PF, ed. Coral reef fishes: dynamics and diversity in a complex ecosystem. San Diego: Academic Press, 391-420.

Simpfendorfer CA. 2005. Demographic models: life tables, matrix models and rebound potential. In: Musick JA, and Bonfil R, editors. Elasmobranch Fisheries Management Techniques. Rome: Food and Agriculture Organisation of the United Nations. p 187-204.

Simpfendorfer CA, and Kyne PM. 2009. Limited potential to recover from overfishing raises concerns for deep-sea sharks, rays and chimaeras. Environmental Conservation 36:97-103. 
509 Smart JJ, Harry AV, Tobin AJ, and Simpfendorfer CA. 2013. Overcoming the constraints of low sample

510 sizes to produce age and growth data for rare or threatened sharks. Aquatic Conservation-Marine

$511 \quad$ and Freshwater Ecosystems 23:124-134.

512 Smith SE, Au DW, and Show C. 1998. Intrinsic rebound potentials of 26 species of Pacific sharks. Marine $513 \quad$ and Freshwater Research 49:663-678.

514 Thorson JT, and Simpfendorfer CA. 2009. Gear selectivity and sample size effects on growth curve $515 \quad$ selection in shark age and growth studies. Fisheries Research 98:75-84.

516 Town C, Marshall A, and Sethasathien N. 2013. Manta Matcher: automated photographic identification of 517 manta rays using keypoint features. Ecol Evol 3:1902-1914.

518 Vincent ACJ, Sadovy de Mitcheson Y, Fowler SL, and Lieberman S. 2013. CITES complements fishery 519 management for sustainable international trade. Fish and Fisheries.

520 Ward-Paige CA, Davis B, and Worm B. 2013. Global population trends and human use patterns of Manta $521 \quad$ and Mobula rays. PLoS ONE 8:e74835.

522 Wintner SP. 2000. Preliminary study of vertebral growth rings in the whale shark, Rhincodon typus, from 523 the east coast of South Africa. Environmental Biology Of Fishes 59:441-451.

524 Yamaguchi A, Kawahara I, and Ito S. 2005. Occurrence, growth and food of longheaded eagle ray, 525 Aetobatus flagellum, in Ariake Sound, Kyushu, Japan. Environmental Biology Of Fishes 74:229$526 \quad 238$. 


\section{Figure legends}

\section{FIGURE 1.}

529 Gill plates, tentatively identified as from the Sickle-fin Devil ray Mobula tarapacana (Philippi,

530 1892), for public sale in downtown Vancouver, British Columbia, Canada on $26^{\text {th }}$ April 2013:

531 photo credit Nicholas K. Dulvy.

\section{FIGURE 2}

533 (a) Maximum intrinsic rate of population increase for 106 chondrichthyans, including the manta 534 ray. (b) Sensitivity of manta ray maximum intrinsic rate of population increase to variation in 535 natural mortality rate, age at maturity and annual reproductive rate.

\section{FIGURE 3.}

537 Maximum intrinsic rate of population increase versus, (a) von Bertalanffy growth rate $k$, and (b) 538 maximum linear dimension $(\mathrm{cm})$ for 106 chondrichthyans on a logarithmic scale. Whale and 539 basking sharks are highlighted for comparison. 


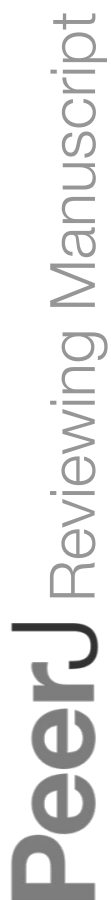

PeerJ reviewing PDF | (v2013:12:1204:1:1:NEW 30 Apr 2014) 


\section{Table 1 (on next page)}

Growth estimates for tropical rays and whale shark

Table 1 - von Bertalanffy growth parameter estimates for species with similar life styles to the manta rays; $a$. tropical myliobatoid rays larger than $1 \mathrm{~m}$ total disc width, and $b$. the tropical planktivorous whale shark. 
1 Table 1. Von Bertalanffy growth parameter estimates for species with similar life styles to the manta rays; $a$. tropical myliobatoid rays larger than $1 \mathrm{~m}$ total disc width, and $b$. the tropical planktivorous whale shark.

\begin{tabular}{|c|c|c|c|c|c|c|c|c|}
\hline & 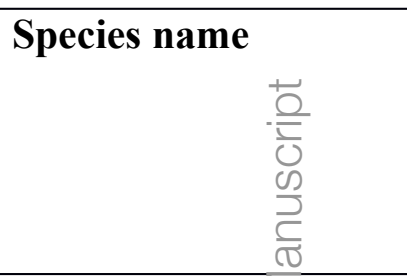 & $\begin{array}{l}\text { IUCN } \\
\text { Status }^{\mathrm{a}}\end{array}$ & Sex & $\begin{array}{l}\text { Maximu } \\
\text { m } \\
\text { length } \\
(\mathrm{cm})^{\mathrm{b}} \\
\end{array}$ & $\begin{array}{l}\text { Maximu } \\
\text { m age } \\
\text { (years) }\end{array}$ & $\boldsymbol{L}_{\infty}$ & $\boldsymbol{k}$ & Reference \\
\hline \multirow[t]{7}{*}{$a$} & Mobula japanica & $N T$ & both & 310 & 14 & NA & 0.28 & (Cuevas-Zimbrón et al. 2012) \\
\hline & Myliobatis califarrnicus & $L C$ & M & 158.7 & 6 & 199.1 & 0.0596 & (Martin \& Cailliet 1988) \\
\hline & Myliobatis califgrnicus & $L C$ & $\mathrm{~F}$ & 158.7 & 24 & 158.7 & 0.0095 & (Martin \& Cailliet 1988) \\
\hline & Myliobatis califórnicus & $L C$ & $\mathrm{~F}$ & 158.7 & 24 & 156.6 & 0.099 & (Martin \& Cailliet 1988) \\
\hline & Aetobatus fla $\overline{g e l D}$ im & $E N$ & $\mathrm{~F}$ & 150 & 19 & 152.7 & 0.111 & (Yamaguchi et al. 2005) \\
\hline & Aetobatus flagerum & $E N$ & M & 100 & 9 & 131.8 & 0.133 & (Yamaguchi et al. 2005) \\
\hline & Rhinoptera bornsus & $N T$ & both & 102 & 18 & 123.8 & 0.075 & (Neer \& Thompson 2005) \\
\hline \multirow[t]{2}{*}{$b$} & Rhincodon typ & $V U$ & NA & 1370 & NA & 1400 & $0.026-$ & (García et al. 2008; Pauly 2002) \\
\hline & & & & & & & 0.051 & \\
\hline
\end{tabular}

3 aUCN Red List Categories: CR, Critically Endangered; EN, Endangered; VU, Vulnerable; NT, Near Threatened; LC, Least Concern; 4 DD, Data Deficient.

$5 \quad{ }^{b}$ Disc width $(\mathrm{cm})$ for rays and total length $(\mathrm{cm})$ for whale shark 


\section{Figure 1}

Image of Devil Ray gill plates for sale in Vancouver

Figure 1: Gill plates, tentatively identified as from the Sickle-fin Devil ray Mobula tarapacana (Philippi, 1892), for public sale in downtown Vancouver, British Columbia, Canada on $26^{\text {th }}$ April 2013: photo credit Nicholas K. Dulvy. 


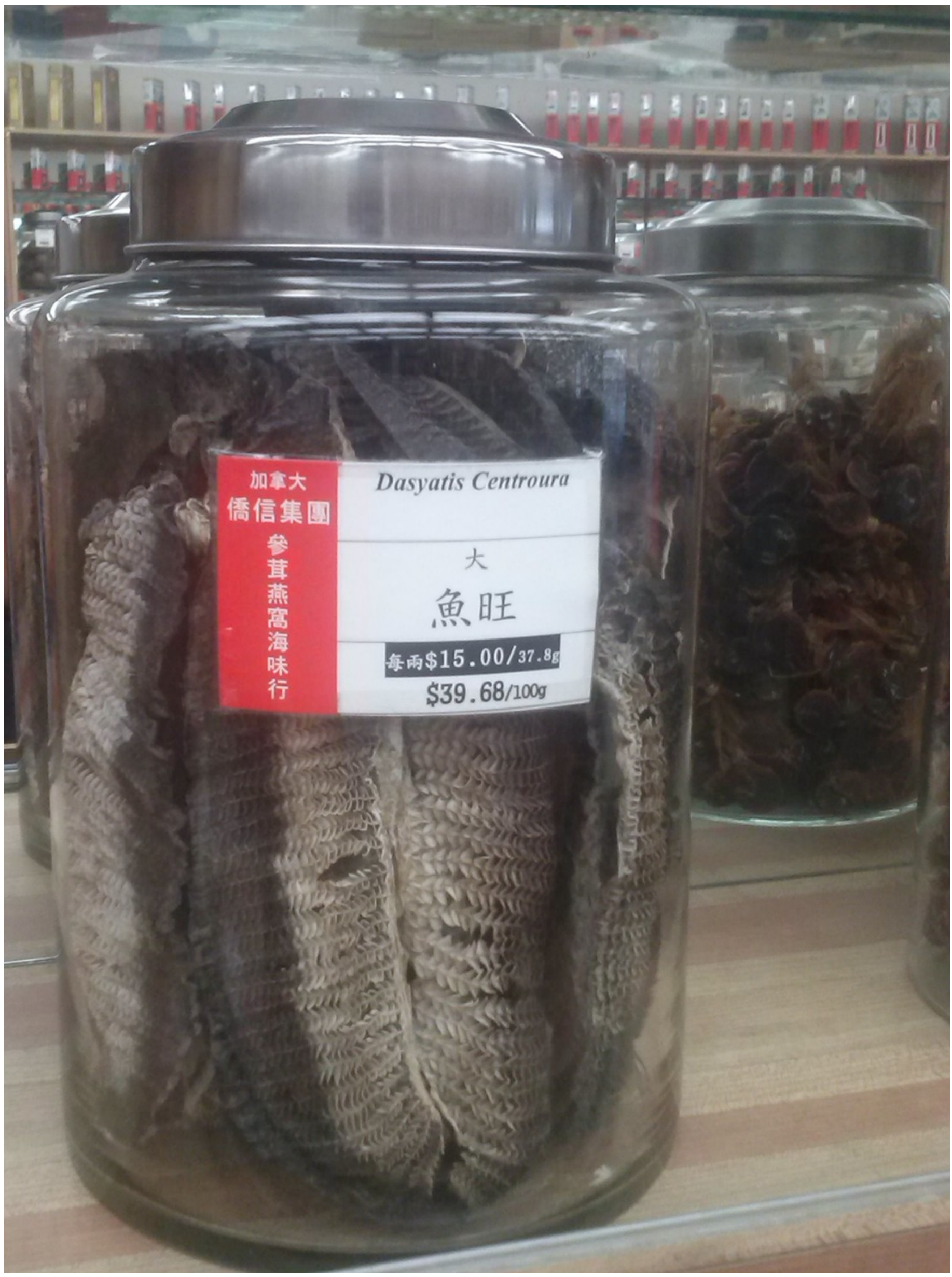




\section{Figure 2}

Maximum intrinsic rate of population increase for 106 chondrichthyans, and the manta ray

Figure 2: (a) Maximum intrinsic rate of population increase for 106 chondrichthyans, including the manta ray. (b) Sensitivity of manta ray maximum intrinsic rate of population increase to variation in natural mortality rate, age at maturity and annual reproductive rate. 

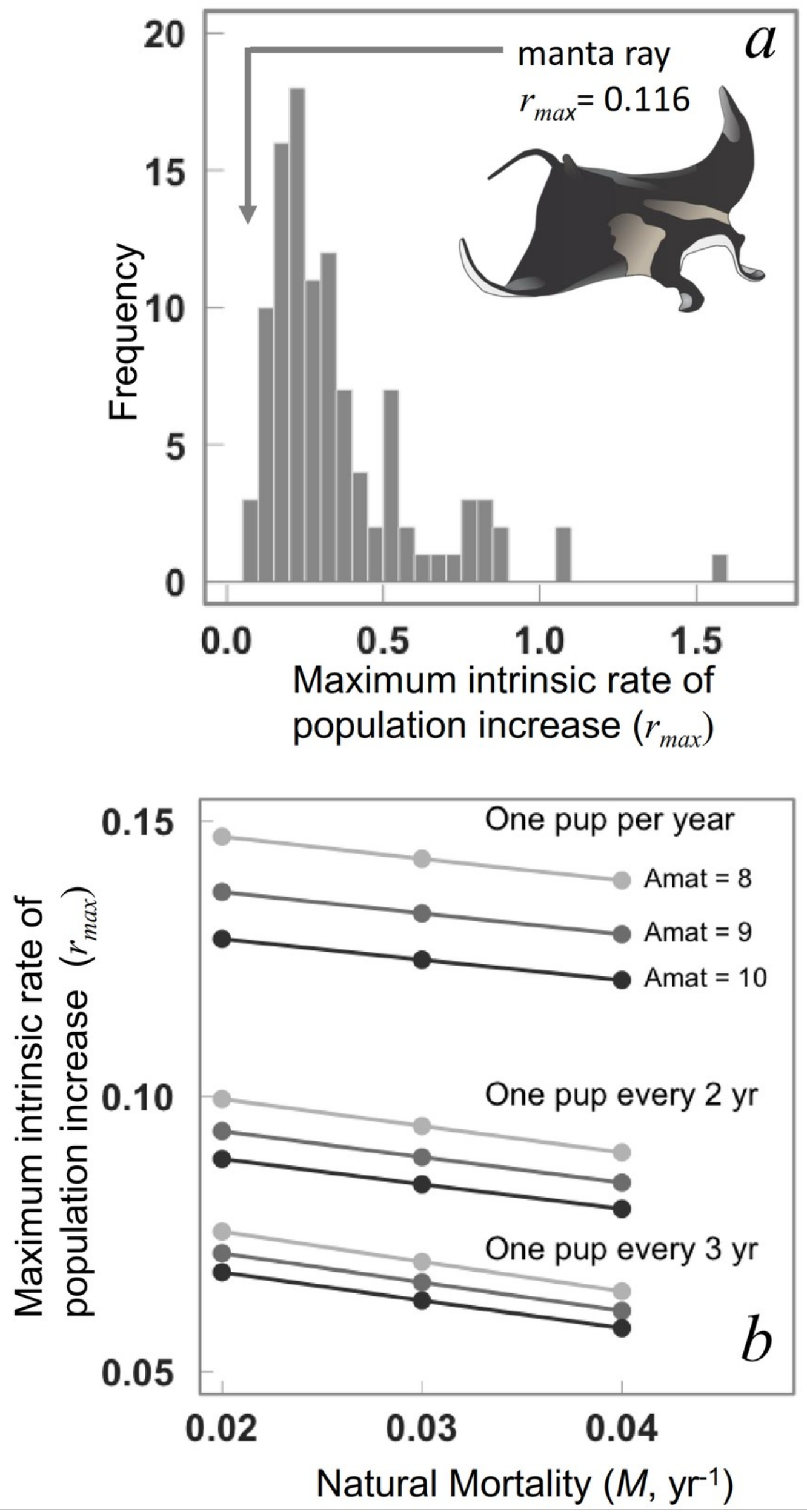


\section{Figure 3}

Manta rays have a low maximum intrinsic rate of population increases due to their low growth rate to a very large size.

Figure 3: Maximum intrinsic rate of population increase versus, (a) von Bertalanffy growth rate $k$, and $(\mathrm{b})$ maximum linear dimension $(\mathrm{cm})$ for 106 chondrichthyans on a logarithmic scale. Whale and basking sharks are highlighted for comparison. [b] 

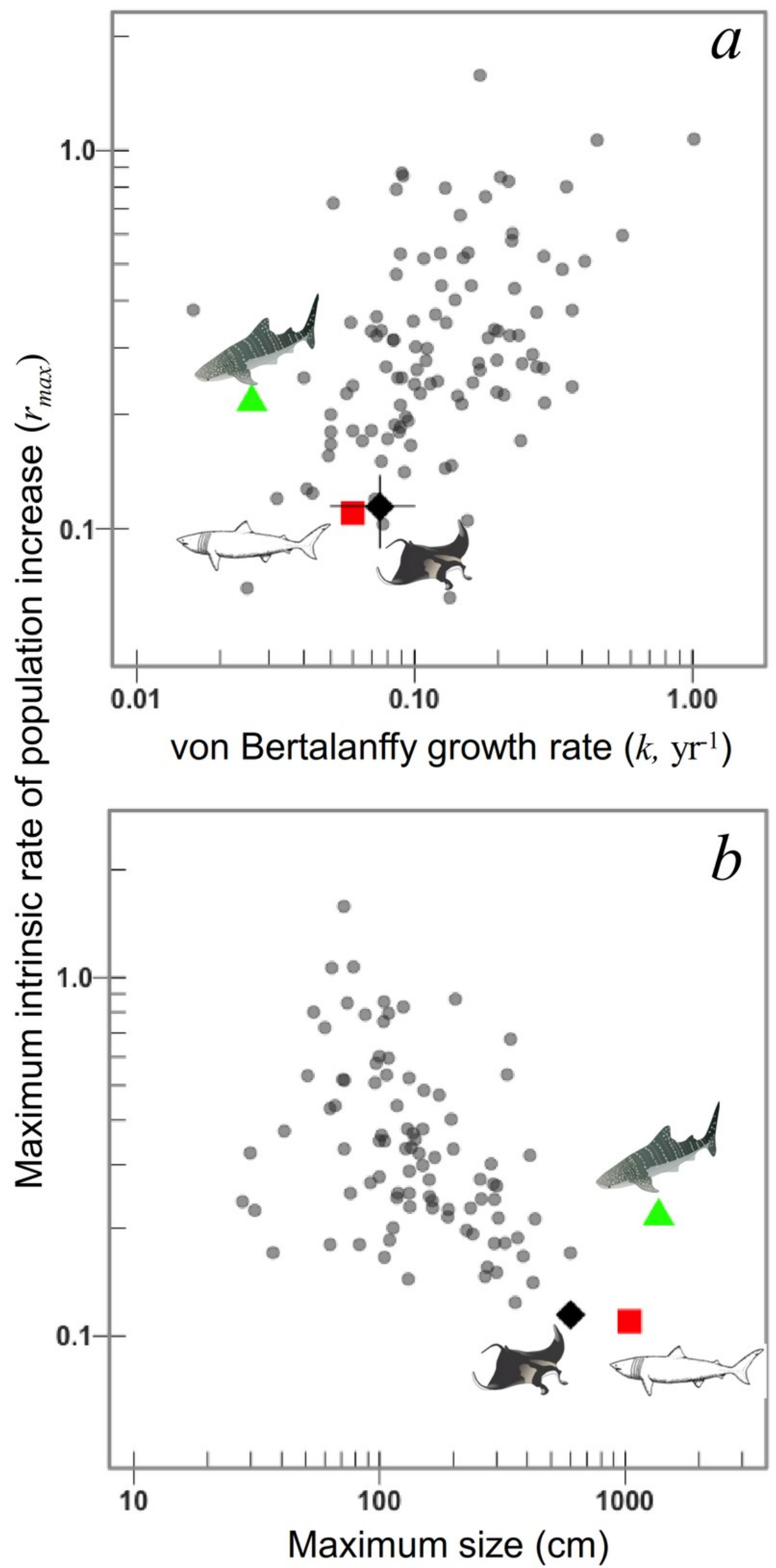